\title{
Placenta previa: outcomes in scarred and unscarred uterus
}

\section{Rajshree Dayanand Katke*}

Department of Obstetrics and Gynaecology, Cama and Albless Hospital, Grant Government Medical College and J. J. Group of Hospitals, Mumbai, Maharashtra, India

Received: 16 June 2016

Accepted: 06 July 2016

\section{*Correspondence:}

Dr. Rajshree Dayanand Katke,

E-mail: drrajshrikatke@gmail.com

Copyright: ( ) the author(s), publisher and licensee Medip Academy. This is an open-access article distributed under the terms of the Creative Commons Attribution Non-Commercial License, which permits unrestricted non-commercial use, distribution, and reproduction in any medium, provided the original work is properly cited.

\begin{abstract}
Background: Placenta previa complicates $0.3 \%-0.5 \%$ of all pregnancies and is a major cause of third-trimester hemorrhage. Almost $30 \%$ maternal deaths in the Asian population are due to major obstetrical haemorrhage in placenta previa, especially due to rise in the incidence of cesearean sections. Significant maternal morbidity in the form of increased incidence of fetalmalpresentation, cesearean delivery, increased blood loss and peripartum hysterectomy have been noted in cases of placenta previa and can lead to prolonged hospitalization in these women. Premature deliveries can occur which lead to higher admission to neonatal intensive care unit and stillbirths.

Methods: This retrospective study was conducted in the Department of Obstetrics and Gynecology at Cama and Albless Hospital (Sir J.J Group of Hospitals), Mumbai. Cases of placenta previa from January 2013 to December 2015 were studied.

Results: Significantly high number of patients delivered before 37 weeks of gestation in Group A $(66.7 \%)$ than that in group B (20\%). ( $\mathrm{p}=0.003$, Hsig). There was only case of placenta accreting in Group A (6.7\%) and only this patient required an obstetric hysterectomy. Both Groups showed a favourable fetal outcome (Group A 100\%, Group B 96\%).

Conclusions: In conclusion, primary prevention in the form of reduction in the rate of primi cesearean section must be done in order to prevent likelihood of placenta previa in scarred uteri. Early diagnosis by Ultrasound and planned delivery should be the goal.
\end{abstract}

Keywords: Placenta previa, Obstetric hysterectomy, Cesearean delivery

\section{INTRODUCTION}

Placenta previa complicates $0.3 \%-0.5 \%$ of all pregnancies and is a major cause of third-trimester hemorrhage. ${ }^{1}$ Almost $30 \%$ maternal deaths in the Asian population are due to major obstetrical haemorrhage in placenta previa, especially due to rise in the incidence of cesearean sections. ${ }^{2}$ Significant maternal morbidity in the form of increased incidence of fetalmalpresentation, cesearean delivery, increased blood loss and peripartum hysterectomy have been noted in cases of placenta previa and can lead to prolonged hospitalization in these women. Premature deliveries can occur which lead to higher admission to neonatal intensive care unit and stillbirths. ${ }^{1}$
Traditionally, placenta previa has been classified according to the degree to which the placenta encroaches upon the cervix in labour, but in recent times, due to easy availability of transvaginal ultrasound, types and grades of placenta previa have been defined. Along with history, clinical examination and ultrasound (transabdominal and transvaginal), MRI (magnetic resonance imaging) has been used in patients with placenta previa, especially to diagnose adherent placenta. It has been speculated that uterine scarring due to trauma, infection or surgery lead to endo-myometrial junction abnormality causingabnormal vascularization which reduces the differential growth of the lower segment. This prevents placental migration as pregnancy advances. ${ }^{1}$ Factors like advanced maternal age, previous placenta previa, 
multiparity, multiple gestation, previous abortion and curettage and smoking during pregnancy have also been associated with placenta previa.,

The aim of this study was to examine the risk factors and outcomes in placenta previa in previously scarred uterus and compare them to placenta previa in unscarred uterus.

\section{METHODS}

This retrospective study was conducted in the Department of Obstetrics and Gynecology at Cama and Albless Hospital (Sir J.J Group of Hospitals), Mumbai. Cases of placenta previa from January 2013 to December 2015 were studied.

Women over 28 weeks of gestation with all types of placenta previa were identified. They were divided into two groups, Group A in which placenta previa occurred in a previously scarred uterus and Group B in which placenta previa occurred in an unscarred uterus.

Both booked cases and unbooked cases were included. Placental localisation was achieved by trans abdominal ultrasounds in these patients.

Risk factors in terms of maternal age, parity, gestational age, previous placenta previa, multiple pregnancies, previous curettage and previous uterine surgery (myomectomy, ceserean section and hysterotomy) were compared.

Chi square test was used to compare quantitative data and $\mathrm{p}<0.05$ was determined to be statistically significant.

\section{Data tabulation}

Total number of deliveries $=6451$

Total number of scarred cases $=1126$

Total number of placenta previa $=40$

Overall incidence of placenta previa $=0.62 \%$

Incidence in scarred uteri $=1.33 \%$

Incidence in unscarred uteri $=0.47 \%$.

\section{RESULTS}

The overall incidence of placenta previa in this study was $0.62 \%$ (Figure 1). The incidence in scarred uterus $(1.33 \%)$ was higher than that in unscarred uterus $(0.47 \%)$ (Figure 2). Majority of the patients in the study were between 25-30 years of age (Group A 53.3\%, Group B $48 \%$ ). $26.7 \%$ of women with scarred uteri were over 36 years of age as compared to $4 \%$ of women in Group B $(\mathrm{p}=0.04$, Sig) (Table 1). There were no primipara with placenta previa in Group A and 28\% in Group B ( $\mathrm{p}=0.01$, Sig) (Table 2).

There was a history of previous placenta previa in $20 \%$ of patients in Group A and 4\% in Group B ( $\mathrm{p}=0.10$, Nsig). (Table 3) High number of patients were unbooked both in Group A $(80 \%)$ and Group B (84\%) ( $\mathrm{p}=0.74$, Nsig). (Table 4$) 75 \%$ of booked and $87.5 \%$ of unbooked cases were anemic ( $\mathrm{p}=0.37$, Nsig) (Table 5).

Table 1: Age distribution of cases.

\begin{tabular}{|llllll|l|}
\hline Age (yrs) & Group a (scarred uterus) & Group b (unscarred uterus) & Total & P value \\
\hline & No. & $\%$ & No. & 10 & $\%$ & \\
\hline$<25$ & 1 & 6.7 & 12 & 40 & $11(27.5 \%)$ \\
\hline $25-30$ & 8 & 53.3 & 2 & 48 & $20(50 \%)$ & P=0.04 \\
\hline $31-35$ & 2 & 13.3 & 1 & 8 & $4(10 \%)$ & Significant \\
\hline$>36$ & 4 & 26.7 & 25 & 100 & $4(12.5 \%)$ \\
\hline Total & 15 & 100 & & & 40 \\
\hline
\end{tabular}

Table 2: Parity Distribution.

\begin{tabular}{|c|c|c|c|c|c|c|}
\hline Parity & \multicolumn{2}{|c|}{ Group a (scarred uterus) } & \multicolumn{2}{|c|}{ Group b (unscarred uterus) } & \multirow[t]{2}{*}{ Total } & P value \\
\hline & No. & $\%$ & No. & $\%$ & & \multirow{5}{*}{$\begin{array}{l}\mathrm{P}=0.01 \\
\text { Significant }\end{array}$} \\
\hline 0 & 0 & 0 & 7 & 28 & $7(17.5 \%)$ & \\
\hline 1 & 13 & 86.7 & 10 & 40 & $23(57.5 \%)$ & \\
\hline$\geq 2$ & 2 & 13.3 & 8 & 32 & $10(25 \%)$ & \\
\hline Total & 15 & 100 & 25 & 100 & 40 & \\
\hline
\end{tabular}


Table 3: Distribution of cases by previous history of placenta previa.

\begin{tabular}{|c|c|c|c|c|c|c|}
\hline Previous placenta previa & \multicolumn{2}{|c|}{ Group a (scarred uterus) } & \multicolumn{2}{|c|}{ Group b (unscarred uterus) } & \multirow[t]{2}{*}{ Total } & \multirow{2}{*}{ P value } \\
\hline & No. & $\%$ & No. & $\%$ & & \\
\hline Yes & 3 & 20 & 1 & 4 & $4(10 \%)$ & \multirow{3}{*}{$\begin{array}{l}\mathrm{P}=0.10 \\
\text { Not significant }\end{array}$} \\
\hline No & 12 & 80 & 24 & 96 & $36(90 \%)$ & \\
\hline Total & 15 & 100 & 25 & 100 & 40 & \\
\hline
\end{tabular}

Table 4: Distribution of booking status.

\begin{tabular}{|c|c|c|c|c|c|c|}
\hline Booking status & \multicolumn{2}{|c|}{ Group a (scarred uterus) } & \multicolumn{2}{|c|}{ Group b (unscarred uterus) } & \multirow[t]{2}{*}{ Total } & \multirow[t]{2}{*}{ P value } \\
\hline & No. & $\%$ & No. & $\%$ & & \\
\hline Booked & 3 & 20 & 4 & 16 & $8(20 \%)$ & \multirow{3}{*}{$\begin{array}{l}\mathrm{P}=0.74 \\
\text { Not significant }\end{array}$} \\
\hline Unbooked & 12 & 80 & 21 & 84 & $32(80 \%)$ & \\
\hline Total & 15 & 100 & 25 & 100 & 40 & \\
\hline
\end{tabular}

Incidence of Grade III and Grade IV placenta previa was highest in Group A (66.7\% each), whereas maximum number of patients in Group B had a Grade 2 placenta previa $(32 \%)(p=0.99$, Nsig). (Table 11) $66.7 \%$ of scarred uteri had anterior placentae, while $68 \%$ of unscarred uteri had posterior placentae ( $\mathrm{p}=0.03$, Sig) (Table 12).
Significantly high number of patients delivered before 37 weeks of gestation in Group A $(66.7 \%)$ than that in group B (20\%). ( $\mathrm{p}=0.003$, Hsig) (Table 6). There was only case of placenta accrete in Group A (6.7\%) and only this patient required an obstetric hysterectomy. (Table 8,9) Both Groups showed a favourable fetal outcome (Group A 100\%, Group B 96\%) (Table 7).

Table 5: Incidence of anemia.

\begin{tabular}{|llllll|l|}
\hline Anemia $(\mathbf{h b}<\mathbf{1 1}$ gm \%) & \multicolumn{2}{l|}{ Booked cases } & \multicolumn{2}{l|}{ Unbooked cases } & Total & P value \\
\hline & No. & $\%$ & No. & $\%$ & & P.37 \\
Nes & 6 & 75 & 28 & 87.5 & $34(85 \%)$ & Not significant \\
\hline No & 2 & 25 & 4 & 12.5 & $6(15 \%)$ \\
\hline Total & 8 & 100 & 32 & 100 & 40 \\
\hline
\end{tabular}

Table 6: Gestational age at delivery.

\begin{tabular}{|llllll|}
\hline Gestational age (wks) & Group a (scarred uterus) & \multicolumn{2}{l|}{ Group b (unscarred uterus) } & Total \\
\hline & No. & $\%$ & No. & $\%$ & $15(37.5 \%)$ \\
\hline$<37$ & 10 & 66.7 & 5 & 20 & $25(62.5 \%)$ \\
\hline$>37$ & 5 & 33.3 & 20 & 80 & P value \\
Significant & \\
\hline Total & 15 & 100 & 25 & 100 & 40 \\
\hline
\end{tabular}

Table 7: Distribution of fetal outcomes.

\begin{tabular}{|lllll|}
\hline Fetal outcome & Group a (scarred uterus) & \multicolumn{3}{c|}{ Group b (unscarred uterus) } \\
\hline Alive & No. & $\%$ & No. & \\
\hline Stillbirths & 15 & 100 & 24 & \\
\hline Neonatal deaths & 0 & 0 & 0 & 96 \\
\hline Total & 0 & & 1 & 0 \\
\hline
\end{tabular}


Table 8: Incidence of Adherent placenta.

\begin{tabular}{|llllll|}
\hline Adherent placenta & Group a (scarred uterus) & \multicolumn{3}{c|}{ Group b (unscarred uterus) } \\
\hline & No. & $\%$ & No. & $\%$ & 0 \\
\hline Placenta accreta & 1 & 6.7 & 0 & 0 & $1(2.5 \%)$ \\
\hline Placenta percreta & 0 & 0 & 0 & 0 & 0 \\
\hline Non adherent placenta & 14 & 93.3 & 25 & 100 & $39(97.5 \%)$ \\
\hline Total & 15 & 100 & 25 & 100 & 40 \\
\hline
\end{tabular}

Table 9: Incidence of obstetric hysterectomy.

\begin{tabular}{|llllll|}
\hline Obstetric Hysterectomy & Group a (scarred uterus) & \multicolumn{2}{l|}{ Group b (unscarred uterus) } & Total \\
\hline Yes & No. & $\%$ & No. & \% & $1(2.5 \%)$ \\
\hline No & 1 & 6.7 & 0 & 0 & 100 \\
\hline Total & 14 & 93.3 & 25 & 100 & $39(97.5 \%)$ \\
\hline
\end{tabular}

Table 10: Requirement of blood transfusion.

\begin{tabular}{|llllll|}
\hline Blood transfusion & Group a (scarred uterus) & Group b (unscarred uterus) & Total & P value \\
\hline & No. & $\%$ & No. & $\%$ & 0.72 \\
Yes & 5 & 33.3 & 7 & 24 & $12(30 \%)$ \\
\hline No & 10 & 66.7 & 18 & 76 & $28(70 \%)$ \\
\hline Total & 15 & 100 & 25 & 100 & 40 \\
\hline
\end{tabular}

Table 11: Distribution of grades of placenta previa.

\begin{tabular}{|c|c|c|c|c|c|c|}
\hline \multirow[t]{2}{*}{$\begin{array}{l}\text { Grades of placenta } \\
\text { previa }\end{array}$} & \multicolumn{2}{|c|}{$\begin{array}{l}\text { Group a (scarred } \\
\text { uterus) }\end{array}$} & \multicolumn{2}{|c|}{ Group b (unscarred uterus) } & \multirow[t]{2}{*}{ Total } & \multirow{2}{*}{$\begin{array}{l}\mathrm{P} \text { value } \\
\mathrm{P}=0.99, \text { Not significant }\end{array}$} \\
\hline & No. & $\%$ & No. & $\%$ & & \\
\hline I & 2 & 13.3 & 4 & 16 & $5(12.5 \%)$ & \\
\hline II & 5 & 33.3 & 8 & 32 & $14(35 \%)$ & \\
\hline III & 4 & 66.7 & 7 & 28 & $11(27.5 \%)$ & \\
\hline IV & 4 & 66.7 & 6 & 24 & $10(25 \%)$ & \\
\hline Total & 15 & 100 & 25 & 100 & 40 & \\
\hline
\end{tabular}

Table 12: Distribution of type of placenta previa.

\begin{tabular}{|c|c|c|c|c|c|c|}
\hline Types of placenta previa & Gro & red uterus) & Gro & carred uterus) & Total & \multirow{5}{*}{$\begin{array}{l}\mathrm{P} \text { value } \\
\mathrm{P}=0.03 \\
\text { Significant }\end{array}$} \\
\hline & No. & $\%$ & No. & $\%$ & & \\
\hline Anterior & 10 & 66.7 & 8 & 32 & $18(45 \%)$ & \\
\hline Posterior & 5 & 33.3 & 17 & 68 & $22(55 \%)$ & \\
\hline Total & 15 & 100 & 25 & 100 & 40 & \\
\hline
\end{tabular}

\section{DISCUSSION}

The overall incidence of placenta previa in our study is $0.62 \%$ which is similar to that found in the study by Gayatri et al $(0.62 \%)$ and Reddy et al $(0.5 \%){ }^{3}$ A slightly higher incidence was found in the study by Ahmed et al $(1.3 \%) .^{2}$ The incidence of placenta previa was higher in the women with previous cesaerean section as compared to those with no previous uterine scar i.e. $1.33 \%$ and $0.47 \%$ respectively. This was comparable to the study by
Gayatri et al (Incidence in scarred uterus $=1.2 \%$ ) and Ahmed et al $(2.2 \%){ }^{2}$

On studying risk factors for placenta previa, it was found that the incidence of placenta previa goes on increasing as maternal age advances. In our study, maximum numbers of women in both scarred (53.3\%) and unscarred group (48\%) were between 25-30 years of age. Significant numbers of women with scarred uteri $(26.7 \%)$ were over 36 years of age as compared to $4 \%$ of women 
in unscarred group. While Gayatri et al reported the incidence of placenta previa as $68 \%$ in 26-30 years in scarred cases and 65\% in 20-25 years in unscarred cases. ${ }^{3}$ Reddy et al reported $73 \%$ incidence in 20-29 years age group. ${ }^{4}$ According to the study by Hung et al, $71.3 \%$ were in age group of 20-35 yrs and $28.5 \%$ over 35 years of age. $^{1}$

Our study shows increasing parity increases with risk of placenta previa, Para 1 or more were $100 \%$ in scarred uterus and $72 \%$ in unscarred uterus. The results are consistent with Reddy et al in which $69 \%$ were multiparous and Gayatri et al Para 3 in scarred uterus was $45 \%$ and in unscarred cases in Para 2 cases, was 30\%. ${ }^{3,4}$

Incidence of placenta 2732 cesaerean is greater in patients with prior 2732 cesaerean section than in unscarred uterus. In our study, $6.7 \%$ out of the scarred uterus constitute placenta 2732 cesaerean and percreta, which is consistent with the study of Gayatri et al $5.8 \%$. $^{3}$ Ahmed et al reported a very high incidence of $26.4 \%$ of adherent placenta in their study, hence concluding that probability of placenta 2732 cesaerean is greater in patients with prior 2732 cesaerean section. ${ }^{2}$

Anterior previa is commoner in patients with previous 2732 cesaerean section. In our study, significantly higher number of $66.7 \%$ cases have anterior previa in scarred uterus and only $32 \%$ cases in unscarred uterus ( $\mathrm{p}$ value $=$ $0.03 \mathrm{~S}$ ). This is comparable to that found in the study by Gayatri et al $85.3 \%$ anterior placenta in scarred uterus and $36.8 \%$ in unscarred uterus. ${ }^{3} 20 \%$ of women in scarred group and $4 \%$ in unscarred group had a previous history of placenta previa in our study. Hung et al reported an incidence of $0.2 \%$ of repeat placenta previa. ${ }^{1}$

Assessment of fetal outcome in terms of premature birth, $66.7 \%$ women had preterm births in scarred uterus group as compared to $20 \%$ in unscarred group $(\mathrm{p}=0.003, \mathrm{HS})$. Similar results were found by Gayatri et al where babies delivered at $<37$ weeks of gestation, $58 \%$ in scarred and $47 \%$ in unscarred group. ${ }^{3}$

There were no still births in our study as compared to $13.2 \%$ in the study by Ahmed et al. ${ }^{2}$ Incidence of still births was $9 \%$ and $24 \%$ in scarred and unscarred group in the study by Gayatri et al. ${ }^{3}$

There was no maternal death in this study as in the study by Ahmed et al. ${ }^{2}$

\section{CONCLUSION}

In conclusion, primary prevention in the form of reduction in the rate of primi caesearean section must be done in order to prevent likelihood of placenta previa in scarred uteri. The emphasis should be on institutional delivery in a tertiary care centre with multidisciplinary care i.e. involvement of senior obstetrician, neonatologist, Sonologist and Haematologist. Early diagnosis by Ultrasound and planned delivery should be the goal.

\section{Funding: No funding sources}

Conflict of interest: None declared

Ethical approval: The study was approved by the Institutional Ethics Committee

\section{REFERENCES}

1. Hung TH, Hsieh CC, Hsu JJ, Chiu TH, Lo LM. Risk factors for placenta previa in an Asian population. International Journal of Gynecology and Obstetrics. 2007;97(1):26-30.

2. Ahmed S. Major Placenta Previa: Rate, Maternal and Neonatal outcomes experience at a tertiary maternity hospital, Sohag, Egypt: a prospective study. JCDR. 2015

3. Mathuriya G, Lokhande P. Comparative study of obstetric outcome between scarred and unscarred uterus in placenta previa cases. Indian Journal of Clinical Practice. 2013;24(6).

4. Reddy R, Latha C. Placenta previa: an analysis of 4 year experience. J Obstet Gynecol India. 1999;53-6.

5. Dashe JS, McIntire DD, Ramus RM, Santos-Ramos R, Twickler DM. Persistence of placenta previa according to gestational age at ultrasound detection. Obstetrics and Gynecology. 2002;99(5, Part 1):6927.

6. Warren R, Arulkumaran S. eds. Best practice in labour and delivery. Cambridge University Press; Accessed on $17^{\text {th }}$ Sep 2009.

7. Rasmussen S, Albrechtsen S, Dalaker K. Obstetric history and the risk of placenta previa. Acta Obstet Gynecol Scand. 2000;79(6):502-7.

8. Faiz AS, Ananth CV. Etiology and risk factors for placenta previa: an overview and meta-analysis of observational studies. J Matern Fetal Neonatal Med. 2003;13(3):175-90.

Cite this article as: Katke RD. Placenta previa: outcomes in scarred and unscarred uterus. Int $\mathbf{J}$ Reprod Contracept Obstet Gynecol 2016;5:2728-32. 